九州大学学術情報リポジトリ

Kyushu University Institutional Repository

\title{
Change in phenoloxidase and its precursor during silkworm (a80 strain) development
}

Yamamoto, Kohj i

The University of Texas Health Center at Tyler

Fujii, Hiroshi

Laboratory of Silkworm Genetics, Graduate School of Bioresource and Bioenvironmental Sciences, Kyushu Uuiversity

Kusakabe, Takahiro

Laboratory of Sericultural Science, Graduate School of Bioresource and Bioenvironmental Sciences, Kyushu Uuiversity

Koga, Katsumi

Laboratory of Sericultural Science, Graduate School of Bioresource and Bioenvironmental Sciences, Kyushu Uuiversity

他

https://doi.org/10.5109/24399

出版情報: 九州大学大学院農学研究院紀要. 45 (2)，pp.487-493，2001-02-28. Kyushu University バージョン：

権利関係 : 


\title{
Change in phenoloxidase and its precursor during silkworm (a80 strain) development
}

\author{
Kohji Yamamoto ${ }^{1,4)}$, Hiroshi Fujii ${ }^{2)}$, Takahiro Kusakabe ${ }^{3)}$, Katsumi Koga ${ }^{3)}$, \\ Yoichi Aso $^{4)}$, and Masatsune Ishiguro*4) \\ 1) The University of Texas Health Center at Tyler, 11937 HWY 271 Tyler TX 75708, U. S. A. \\ 2) Laboratory of Silkworm Genetics, ${ }^{3)}$ Laboratory of Sericultural Science, and \\ 4) Laboratory of Protein Chemistry and Engineering, Graduate School of \\ Bioresource and Bioenvironmental Sciences, Kyushu University, \\ 6-10-1 Hakozaki, Higashi-ku, Fukuoka 812-8581, Japan. \\ (Received October 31, 2000 and accepted November 10, 2000)
}

\begin{abstract}
The changes in phenoloxidase and its precursor, so-called prophenoloxidase, of the silkworm, Bombyx mori (a80 strain) were examined using detection assay with or without detergent to distinguish PO and pro-PO in hemolymph (Yamamoto, et al., 1999). Little or no phenoloxidase activity was detected in hemolymph at the silkworm development during the final larval instar and pupal stage. On the other hand, prophenoloxidase was detected for same time frame. In males, after prophenoloxidase increased slightly at day 4 , it decreased to a minimum level at spinning and increased to a maximum level on the day of pupation and decreased gradually to day 5 after pupation. In females, prophenoloxidase decreased gradually to a minimum level on day of spinning and a slight increase was observed at day 8 and it increased to maximum level between day 2 and 3 after pupation and decreased thereafter. Prophenoloxidase mRNA expression was preceded a day or two before, when comparing the change of phenoloxidase mRNA with its product.
\end{abstract}

\section{INTRODUCTION}

Phenoloxidase (PO: monophenol, dihydroxyphenylalanine; oxygen oxidoreductase; EC 1. 14. 18. 1) catalyzes two sequential reactions; the hydroxylation of monophenol to $o$-diphenol and the oxidation of $o$-diphenol to o-quinone (Ashida and Yamazaki, 1990). In insects, PO is generally believed to be crucial for the cuticular melanization and sclerotization (Söderhäll, 1982; Hiruma and Riddiford, 1988; Sugunaran et al., 1992).

The existence of a precuesor protein, called prophenoloxidase (pro-PO), was reported from many insects: e.g., the fruit fly Drosophila melanogaster (Fujimoto et al., 1993), the silkworm Bombyx mori (Yasuhara, et al., 1995; Yamamoto, et al., 1999), the tabacco hornworm Manduca sexta (Hall, et al., 1995), the cockroach Blaberus discoidailis (Durrant, et al., 1993), the wax moth Galleria mellonella (Kopacek, et al., 1995), and a coleopteran insect Holotrichia diomphalia (Kwon, et al., 1997). The activation of pro-PO have been shown by the prophenoloxidase-activating factor in vitro (Lee, et al., 1998; Jiang, et al., 1998; Satoh, et al., 1999) and by organic compounds such as sodium dodecyl sulfate (Funatsu and Inaba, 1962; Inaba and Funatsu, 1964), cetylpyridinium chloride (Hall, et al., 1995), 2-propanol (Asada, et al., 1993) and dimetylbenzylmyristylammonium chloride (DBMA) (Yamamoto, et al., 1999). Futhermore, the

\footnotetext{
* Corresponding author. FAX number: 092-642-3051, E-mail: ishiguro@agr.kyushu-u.ac.jp.
} 
cDNA encoding pro-PO have been cloned and sequenced recently from the mosquite Armigeres subalbatus (Cho, et al., 1998), the malaria vector Anopheles gambiae (Jiang, et al., 1997), the fall webworm Hypantria cunea (Park, et al., 1997), the coleopteran insect Tenebrio molitor (Lee, et al., 1999), the fruit fly D. melanogaster (Fujimoto, et al., 1995), the tabacco hornworm M. sexta (Hall, et al., 1995), and the silkworm B. mori (Kawabata, et al., 1995; Yamamoto, et al., 2000).

Although many knowleges about pro-PO have been accumulated as described above, the biochemical and genetical aspects of the regulation of $\mathrm{PO}$ activity during development is still poorly understood. In housefly, Musca domestica, the change of PO activity was examined from larvae to pupae (Funatsu and Inaba, 1962). The authers found that the noticeable change in PO activity occurred at the stage of pupation. Almost the highest $\mathrm{PO}$ activity in the homogenate of the final instar larvae disappeared suddenly in the homogenate of the prepupae and then it is appeared again in the homogenate of aged pupae. However, the disappearance of PO activity in the prepupae did not imply that the enzyme vanished because the homogenate of the prepupae exhibited $P O$ activity upon the addition of an anionic detergent such as sodium oleic acid or an extract from the aged pupae. It means that phenoloxidase is present as inactive form in prepupae and there is natural activator, which converts inactive form to active form, in aged pupae.

The fluctuation of PO activity during metamorphosis in the silkworm has never investigated. In order to get a better understanding of the regulatory events involved in the metamorphosis of the silkworm, we analyzed the change in PO activity and pro-PO during developmental stages. The comparison of these fluctuations with that for pro-PO mRNA was also included.

\section{MATERIALS and METHODS}

\section{Insects and preparation of hemolymph and hemocytes}

The a80 strain of $B$. mori was reared as described previously (Yamamoto, et al., 1999). Females and males were distinguished by the imaginal bud on the abdominal surface. The hemolymph specimens collected into liquid nitrogen, were lyophilized and the powder obtained was used for the determination of total PO activity.

\section{Measurement of $P O$ activity in the crude extract}

PO activity was measured spectrophotometrically with or without a cationic detergent, DBMA, as an activator (Yamamoto, et al., 1999). The lyophilized hemolymph $(5 \mathrm{mg})$ from various days was dissolved in $1 \mathrm{ml}$ of $10 \mathrm{mM}$ potassium phosphate buffer $(\mathrm{pH}$ 7.0). Fifty $\mu \mathrm{l}$ of this mixture was added to the reaction mixture $(1 \mathrm{ml})$ containing $0.05 \mathrm{M}$ potassium phosphate buffer ( $\mathrm{pH} 6.5$ ), $5 \mathrm{mM} \mathrm{L}-3-(3,4-$ dihydroxyphenyl) alanine (L-dopa) and with or without $0.4 \mathrm{mM} \mathrm{DBMA}$. While incubating at $30^{\circ} \mathrm{C}$ for $0.5 \mathrm{~min}$, the absorbance at $475 \mathrm{~nm}$ was monitored with a Hitachi U-3210 spectrophotometer (Tokyo, Japan). One unit of PO was defined as the amount of active PO capable of producing $1 \mu$ mole of dopachrome per $\min$.

\section{Measurement of pro-PO mRNA titer}

Northern hybridization was done according to previous paper (Yamamoto, et al., 
2000). Level of pro-PO mRNA was assessed by scanning of the electrophoregram by densitometry using NIH image software and replotted.

\section{RESULTS and DISCUSSION}

\section{Change in PO and pro-PO at developmental stages}

The fluctuation of PO activity during metamorphosis in the silkworm has never investigated. Therefore, we measured the fluctuation of $\mathrm{PO}$ or pro-PO and we made better use of detection assay with or without DBMA to distinguish PO and pro-PO in hemolymph.

By using this method, little or no PO was detected, even if the metamorphosis from larva to pupar was occurred (Fig. 1). In housefly, however, the endogeneous PO activity was detected in the homogenate of the final instar larvae, and then it was disappeared suddenly in the homogenate of the prepupae (Funatsu and Inaba, 1962). The presence of active $\mathrm{PO}$ in hemolymph is thought to be harmful to the insects health and it is neccesary to activate it during a need. Therefore, insects need to control active PO. Recently, endogeneous PO inhibitors were identified in the housefly, $M$. domestica (Daquinag, et al., 1995) and in the tabacco hornworm, M. sexta (Sugumaran and Nellaiappan, 2000) and both were shown to inhibits directly the activity of PO. The PO inhibitor of housefly could inhibit PO activity of silkworm (Yamamoto, et al., 2000, unpublished results). This fact suggests that there might be the strong inhibitor in the silkworm that involves in the regulation system of $\mathrm{PO}$ activity, because active $\mathrm{PO}$ cannot be detected.

When the changes in pro-PO was determined in hemolymph at developmental stages from fifth larval instar to pupa, pro-PO was detected for thirteen days from larva to pupa (Fig. 1). In males, after pro-PO increased slightly at day 4 , it decreased to a minimum level $\left(1.39 \times 10^{-3}\right.$ unit/mg lyophilized hemolymph) at spinning (day 6) and increased to a maximum level $\left(7.54 \times 10^{-3}\right.$ unit/mg lyophilized hemolymph) on the day of pupation and decreased gradually to day 5 after pupation. In females, pro-PO decreased gradually to a minimum level on day of spinning $\left(2.41 \times 10^{-3} \mathrm{unit} / \mathrm{mg}\right.$ lyophilized hemolymph $)$ and a slight increase was observed at day 8 and it increased to maximum level $\left(9.80-9.74 \times 10^{-3}\right.$ unit/mg lyophilized hemolymph) between day 2 and 3 after pupation and decreased thereafter. Pro-PO is always present in this period, whereas no active PO was detected. As shown in Fig. 1, the large amount of pro-PO is stored during a few days after pupation. It is postulated that pro-PO in hemolymph was thought to be stored in case of emergency. Xiao-Qiang et al. demonstrated that after injection of bacteria, novel lectin mRNA appeared and lead to stimulate the activation of pro-PO (Yu, et al., 1999).

There is a possibility that some chymotrypsin inhibitors had the ability to inhibit pro--PO activating factor of the same species (Aso, et al., 1994). It was reported some inhibitors found from the locust Locusta migratoria (Brehelin, et al., 1991) and M. sexta (Saul, et al., 1986) could control pro-PO activation. Pro-PO is always present from larva to pupa, whereas no PO activity is detected (Fig. 1). This result indicates that chymotrypsin inhibitor is likely to control pro-PO activation.

We have recently investigated the developmental changes of mRNA titer in the silkworm, B. mori (Yamamoto, et al., 2000). The strong signal of mRNA was detected on day 3 of the fifth instar and one day before pupation in males, whereas females exhibited those on day 4 of the fifth instar and on the day of pupation. Similar results were obtained 


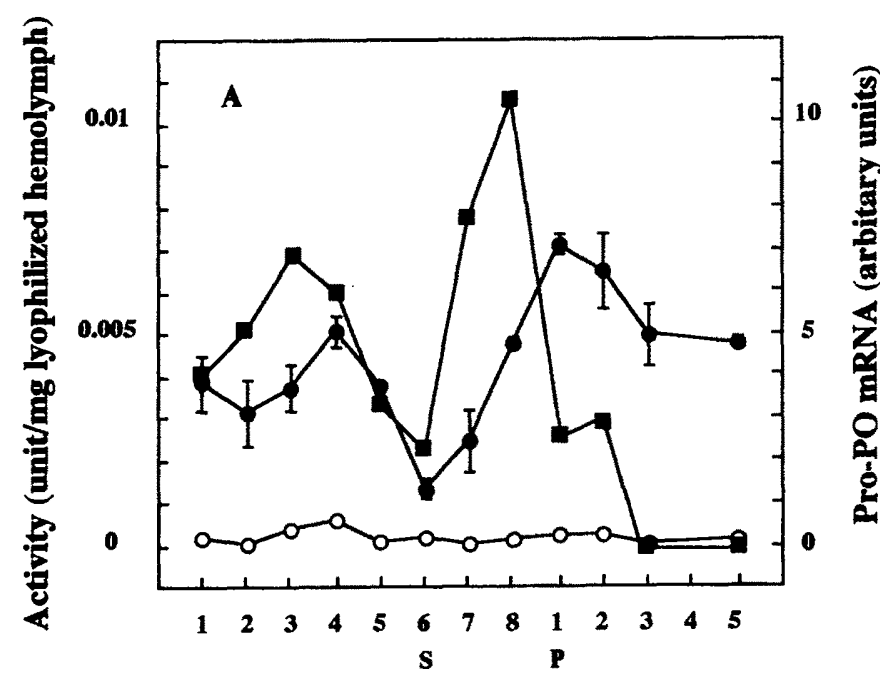

Developmental stages (d)

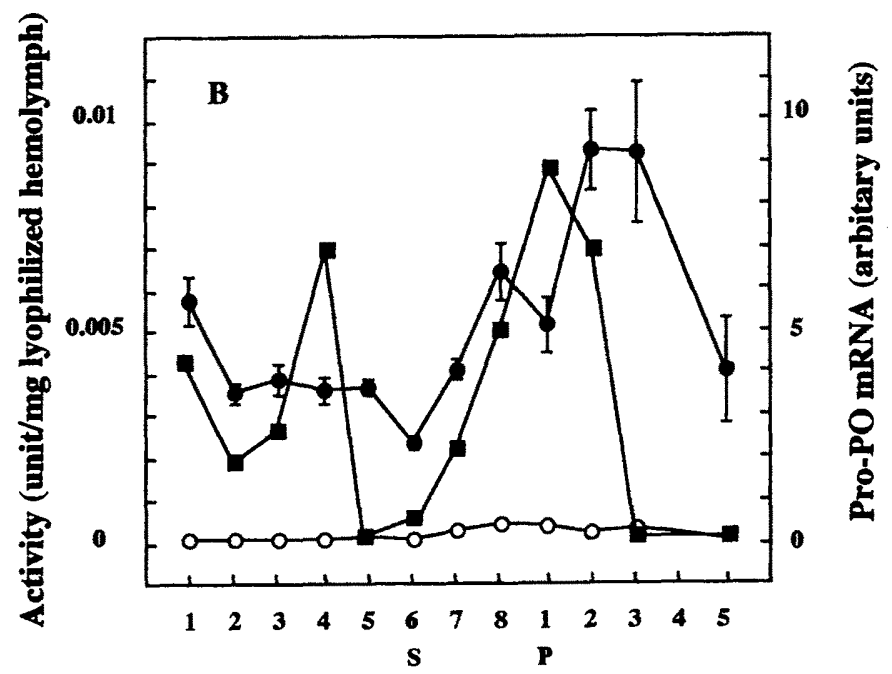

Developmental stages (d)

Fig. 1. Developmental changes in pro-PO content evaluated with $P O$ activity and Pro-PO mRNA

PO activity of crude extract was measured after activation with DBMA as described in Materials and Methods. Closed circles represent the assay conducted in the presense of DBMA. Open circles represent the assay conducted in the absense of DBMA. Closed squares represent the level of mRNA. S and P represent spinning and pupation, respectively. Bars indicate the standard deviation $(\mathrm{n}=3)$. 
when the pro--PO concentrations were measured by enzyme-linked immunosorbent assay.

It is interesting that the fluctuation of pro-PO mRNA of the silkworm was different from that of the fall webworm, $H$. cunea (Park, et al., 1997). They demonstrated that the highest level of pro-PO mRNA was detected in the mid-instar larvae and there was no signal in pupae, adult and egg. There is also the difference between the fluctuation of the silkworm PO and that of housefly PO (Daquinag, et al., 1995). In the housefly, $M$. domestica, by a Western blot detection method using polyclonal antibodies raised against housefly $\mathrm{PO}$, no significant change in PO protein content was observed in the homogenates of the pharate adult compared with that of the homogenates of other stages of aged pupae. They suggested that phenoloxidase inhibitor functions as a regulator of the necessary level of PO.

As shown in Fig. 1, pro-PO mRNA expression was preceded a day or two before, when comparing the change of phenoloxidase mRNA with its product. This finding suggests that the expression of pro-PO could be controlled at transcriptional step. Insect development is known to be regulated by ecdysteroids and juvenile hormones (JH). Possible roles of these hormones in the control of pro-PO expression during development will be studied in detail. The effects of $\mathrm{JH}$ on the synthesis of $\mathrm{PO}$ were reported. The granular PO that is responsible for cuticular melanization in $M$. sexta larva was controlled by JH (Hiruma, K. and Riddiford, L. M., 1984, 1985 and 1988). Recently, the transcription of PO in A. gambiae was regulated by 20-hydroxyecdysone (Martin, et al., 1999). It is also possible for PO synthesis in silkworm to be controlled by 20 -hydroxyecdysone at transcription level. Taken together, there are three possibilities of the regulation mechanism of PO activity, that is, transcriptional control, activation control and the inhibition of active PO. In future research, it is important for us to look for PO inhibitor and we will endeavor to understand how this hormone regulates the expression of $\mathrm{PO}$.

\section{REFERENCES}

Asada, N., Fujimoto, K., Tanaka, M., and Ohnishi, E. 1993 Genetic polymorphism of phenoloxidase A1 in Drosophila melanogaster. Jpn. J. Genet., 68: 217-219

Ashida, M., Ochiai, M., and Niki, T. 1988 Immunolocation of prophenoloxidase among hemocytes of the silkworm, Bombyx mori. Tissue Cell, 20: 599-610

Ashida, M., and Yamazaki, Y. I. 1990 In "Molting and Metamorphosis", ed. by Ohnishi, E. and Ishizaki, H., Japan Scientific Societies Press, Tokyo, pp. 239-265

Aso, Y., Yamashita, T., Meno, K., and Murakami, M. 1994 Inhibition of the prophenoloxidase-activating enzyme from Bombyx mori by endogenous chymotrypsin inhibitors. Biochem. Mol. Biol. Int., 33: $751-758$

Brehelin, M., Boigegrain, R. A., Drif, L., and Coletti-Previero, M. A. 1991 Purification of a protease inhibitor which controls prophenoloxidase activation in hemolymph of Locusta migratoria (insecta). Biochem. Biophys. Res. Commun., 179, 841-846

Cho, W. L., Liu, H. S., Lee, C. H., Kuo, T. Y., Chang, T. Y., Liu, C. T., and Chen, C. C. 1998 Molecular cloning, characterization and tissue expression of prophenoloxidase cDNA from the mosquito Armigeres subalbatus inoculated with Dirofilaria immitis microfilariae. Insect Mol. Biol., 7: $31-40$

Daquinag, A. C., Nakamura, S., Takao, T., Shimonishi, Y. and Tsukamoto, T. 1995 Primary structure of a potent endogenous dopa-containing inhibitor of phenol oxidase from Musca domestica. Proc. Natl. Acad. Sci. USA, 92: 2964-2968

Durrant, H. J., Ratcliffe, N. A., Hipkin, C. R., and Söderhäll, K. 1993 Purification of the pro-phenol 
oxidase enzyme from hemocytes of the cockroach Blaberus discoidalis. Biochem. J., 289: 87-91

Fujimoto, K., Masuda, K., Asada, N., and Ohnishi, E. 1993 Purification and characterization of prophenoloxidases from pupae of Drosophila melanogaster. J. Biochem., 113: 285-291

Fujimoto, K., Okino, N., Kawabata, S., Iwanaga, S., and Ohnishi, E. 1995 Nucleotide sequence of the cDNA encoding the proenzyme of phenol oxidase Al of Drosophila melanogaster. Proc. Natl. Acad. Sci. USA, 92, 7769-7773

Funatsu, M. and Inaba, T. 1962 Studies on tyrosinase in housefly. Part I. Protyrosinase in the pupae of housefly and its activation, Agric. Biol. Chem., 26, 535-540

Hall, M., Scott, T., Sugumaran, M., Söderhäll, K., and Law, J. 1995 Proenzyme of Manduca sexta phenol oxidase: purification, activation, substrate specificity of the active enzyme, the molecular cloning. Proc. Natl. Acad. Sci. USA, 92: 7764-7768

Hiruma, K., and Riddiford, L. M. 1988 Granular phenoloxidase involved in cuticular melanization in the tobacco hornworm: regulation of its synthesis in the epidermis by juvenile hormone. Dev. Biol., 130: $87-97$

Inaba, T. and Funatsu, M. 1964 Studies on tyrosinase in the housefly. Part III Activation of protyrosinase by natural activator. Agric. Biol. Chem., 28: 206-215

Jiang, H., Wang, Y., Korochkina, S. E., Benes, H., and Kanost, M. R. 1997 Molecular cloning of cDNAs for two pro-phenol oxidase subunits from the malaria vector, Anopheles gambiae. Insect Biochem. Mol. Biol., 27: 693-699

Jiang, H., Wang, Y., and Kanost, M. R. 1998 Pro-phenol oxidase activating proteinase from an insect, Manduca sexta: A bacteria-inducible protein similar to Drosophila easter. Proc. Natl. Acad. Sci. USA, 95: 12220-12225

Kawabata, T., Yasuhara, Y., Ochiai, M., Matsuura, S., and Ashida, M. 1995 Molecular cloning of insect pro-phenol oxidase: A copper containing protein homologous to arthropod hemocyanin. Proc. Natl. Acad. Sci. USA, 92: 7774-7778

Kwon, T. H., Lee, J. H., Lee, J. S., Kawabata, S., Iwanaga, S., and Lee, B. L. 1997 Purification and characterization of prophenoloxidase from the hemolymph of coleopteran insect, Holotrichia dimophalia larvae. Mol. Cells, 28: 90-97

Kopacek, P., Weise, C., and Gotz, P. 1995 The prophenoloxidase from the wax moth Galleria mellonella: purification and characterization of the proenzyme. Insect Biochem. Mol. Biol., 25 : 1081-1091

Lee, S. Y., Kwon, T. H., Hyun, J. H., Choi, J. S., Kawabata, S., Iwanaga, S., and Lee, B. L. 1998 In vitro activation of pro-phenol-oxidase by two kinds of pro-phenol-oxidase-activating factors isolated from hemolymph of coleopteran, Holotrichia dimophalia larvae. Eur. J. Biochem., 15: 50-57

Lee, H. S., Cho, M. Y., Lee, K. M., Kwon, T. H., Homma, K., Natori, S., and Lee, B. L. 1999 The pro-phenoloxidase of coleopteran insect, Tenebrio molitor, larvae was activated during cell clump/cell adhesion of insect cellular defense reactions. FEBS Lett., 444: 255-259

Martin, A. D., Manetti, A. G. O., Han, S. -J., Lee, W. -J., Mathiopoulos, K. D., Muller, H. -M., Kafatos, F. C., Raikhel, A., and Brey, P. Y. 1999 Genomic structure and ecdysone regulation of the prophenoloxidase 1 gene in the malaria vector Anopheles gambiae. 96 (26), 14796-14800

Park, D., Shin, S. W., Kim, M. G., Park, S. S., Lee, W., Brey, P. T., and Park, H. 1997 Isolation and characterization of the cDNA encoding the prophenoloxidase of fall webworm, Hyphantria cunea. Insect Biochem. Mol. Biol., 27: 983-992

Satoh, D., Horii, A., Ochiai, M., and Ashida, M. 1999 Prophenoloxidase-activating enzyme of the silkworm, Bombyx mori. Purification, characterization, and cDNA cloning. J. Biol. Chem., 274: $7441-7453$

Saul, S. J. and Sugumaran, M. 1986 Protease inhibitor controls prophenoloxidase activation in Manduca sexta. FEBS Lett, 208: 113-116

Söderhäll, K. 1982 Prophenoloxidase activating system and melanization- a recognition mechanism of arthropods? A review. Dev. Comp. Immunol., 6: 601-611

Sugumaran, M., Giglio, L., Kundzicz, H., Saul, S., and Semensi, V. 1992 Studies on the enzymes involved in puparial cuticle sclerotization in Drosophila melanogaster. Arch. Insect Biochem. Physiol., 19: 271-283

Sugumaran, M. and Nellaiappan, K. 2000 Characterization of a new phenoloxidase inhibitor from the cuticle of Manduca sexta, Biochem. Biophys. Res. Commun., 268: 379-383 
Yamamoto, K., Sugioka, M., Fujii, H., Aso, Y., and Ishiguro, M. 1999 Isolation and characterization of prophenoloxidase isoforms from the silkworm, Bombyx mori (a80 strain). J. Seric. Sci. Jpn., 68: 65-72

Yamamoto, K., Yakiyama, M., Fujii, H., Kusakabe, T., Koga, K., Aso, Y., and Ishiguro, M. 2000 Expression of prophenoloxidase mRNA during silkworm hemocyte development. Biosci. Biotechnol. Biochem., 64: (6), 1197-2000

Yasuhara, Y., Koizumi, Y., Katagiri, C., and Ashida, M. 1995 Reexamination of properties of prophenoloxidase isolated from larval hemolymph of the silkworm Bombyx mori. Arch. Biochem. Biophys., 320: 14-23

Yu, X. -Q., Gan, H., and Kanost, M. R. 1999 Immulectin, an inducible C-type lectin from an insect, Manduca sexta, stimulates activation of plasma prophenol oxidase. Insect Biochem. Mol. Biol., 29: 585-597 